\title{
THE DIFFERENTIAL DIAGNOSIS AND TREATMENT OF TIC DOULOUREUX
}

\author{
By John Penman, M.B., M.R.C.P. \\ Neurologist, Hertford County Hospital, Clinical Assistant, St. George's Hospital and Clinical Assistant, the Maida Vale \\ Hospital for Nervous Diseases
}

It is hard to say which is more unfortunate, the patient with tic douloureux near to suicide after years of vain search for medical help, or the patient who having had a rhizotomy or alcohol injection for some other facial pain now longs to be rid of his numbness and have his former symptom back. Both tragedies may be avoided by precise diagnosis and by restraint in giving radical treatment.

\section{Diagnosis of Tic Douloureux}

Chronic paroxysmal trigeminal neuralgia, or tic douloureux, ought not to be called ' trigeminal neuralgia,' for this vague term covers any pain caused by any lesion of the trigeminus. Tic douloureux is a most definite clinical entity, doubtful cases of which are very rare.

In the diagnosis little help is to be had from the past history, the family history or physical examination, and none from any special investigation. There is only one constant feature, the symptom of pain. This pain is unilateral, trigeminal, severe, paroxysmal and precipitated.

I. Unilateral. Approximately 5 per cent. of cases become in a certain limited sense bilateral, usually years after the onset. Often the second side remains unaffected until the pain on the first side has been cured; the case is then bilateral only in retrospect. Only rarely do the bouts of pain on the two sides overlap in time, or coincide, and even then there are no simultaneous bilateral paroxysms. Be the case unilateral or bilateral, the pain at any given moment neither begins on both sides nor passes from one side to the other.

2. Trigeminal. The pain always originates in the trigeminal area, is always most severe within it, and is usually, but not always, confined to it. This area is subject to normal variation; a patient of mine had an apparently anomalous painful trigger zone over the mastoid process, but after alcohol injection there was analgesia in a strip of scalp about $3 \mathrm{~cm}$. wide behind the ear, including this trigger zone. Occasionally one finds a truly extratrigeminal radiation (Hutchinson, 1905; Head, I910; Cushing, 1920a).
3. Severe. The pain is often agonizing from the moment of onset, and nearly always within a year or two it becomes the worst in the patient's experience. If in the early stages he denies that it is severe, he usually means that the paroxysms, though intense, are too brief and infrequent to be a burden.

4. Paroxysmal implies sudden beginning, sudden end, short duration and symptomless intervals. This is the typical picture, but brief lesser sensations, uncomfortable or painful, may herald or follow the paroxysm. The duration is commonly anything from a split second to 5 minutes, less often ro minutes, rarely still longer. Some patients state convincingly that a few of their paroxysms have been of a really exceptional length, such as half an hour. No absolute limit can be given, but a case in which the usual length of paroxysms was a quarter of an hour would be a rarity. In a few cases a continuous ache is felt in the affected areas, but its severity never approaches that of the paroxysms.

5. Precipitated. The commonest precipitants, in approximate order of frequency, are chewing, talking, washing or otherwise touching the affected side of the face, the mere presence of food in the mouth, head movements, bodily exertion, jarring of the feet in walking and cold winds. They may nearly all be classified as jaw movements, tactile stimuli, factors raising the blood pressure or blends of these. Swallowing is an infrequent precipitant and never the foremost one. Though in every case some paroxysms are precipitated, in most cases some also are spontaneous. Most patients will volunteer three or four precipitants, and more than one is required for the diagnosis, since chewing, for example, may precipitate dental pain and exertion a psychogenic pain.

Given all five of these features the diagnosis is made; the absence of even one of them precludes it. Table I shows the relative importance of these and some other features.

Trigger zones almost certainly occur in no other disease. A light touch on these small areas of skin or mucous membrane is particularly apt to pro- 
voke the characteristic pain; this is felt usually in the area touched but sometimes at some different site which may be even in another main division of the trigeminus.

Phase of inhibition. Some patients find that for a short while after one paroxysm it is impossible to bring on another, a fact of which they make use while eating.

Constant tempo. The stabs or flashes composing the paroxysm have in many cases a fixed rate or a rate which varies according to a fixed pattern.

Certain sites. The two lower divisions are involved about equally commonly. In the mandibular division the pain tends to affect the gum, and less often the lip or tongue; in the maxillary division, the lip and the side of the nose, and less often the gum (Jefferson, 193I). These are only generalizations, but a doubtful case would be all the more doubtful if the pain were confined, say, to the temple. The ophthalmic division is affected in not more than 5 or 10 per cent. of cases and nearly always after the maxillary; an onset only in the ophthalmic division is rare but not unknown.

Constant linear motion. In many cases there are certain fixed tracks which the individual flashes of pain follow with great regularity and in one direction. It is not true, though some have maintained it, that these tracks always correspond to the courses of the main branches of the trigeminus.

The willingness of the patient for permanent facial numbness is a good practical guide to treatment, but it should not be made a diagnostic criterion. Patients with early tic douloureux are often unwilling; those with facial pain caused by cancer, for example, are often willing.

Autonomic nervous disturbances commonly found on the affected side during paroxysms are reddening and watering of the eye, running of the nostril, reddening of the cheek and salivation. They are not diagnostic; McAuliffe and others (1943) produced most of them by painful stimuli to the nasal mucosa.

Normality of the trigeminus on clinical examination is usual, but slight abnormalities may be found. In severe cases the painful areas may be hyperalgetic. On the other hand, Lewy and Grant (1938) showed by electrical tests that in about 30 per cent. of cases there is hypalgesia on the affected side of the body, involving either the face alone or the face and other parts such as the hand. Ordinary tests with a pin occasionally show the same abnormalities. The corneal reflex on the affected side may be somewhat diminished. These changes are never gross; facial analgesia and absence of the corneal reflex are not found.

The mythical 'points de Valleix' were tender areas over the exit foramina of the trigeminal branches. Belief in them is not dead.

\section{Differential Diagnosis}

Dental pain may occur in severe paroxysms precipitated by chewing, but in addition there is usually continuous aching pain, hardly less severe, and other precipitants are lacking. The same applies to the pain of sinusitis, except that chewing does not precipitate it.

Atypical neuralgia has been carefully analysed by Glaser (1928), who emphasized that all treatment is unavailing. Trigeminal rhizotomy and alcohol injection are all too often tried and always add to the patient's misery. The pain of this condition is aching, burning, throbbing or shooting, exacerbated by cold, fatigue, draughts and excitement, and often accompanied by lacrimation and reddening of the skin of the face. The distinguishing features are these: the pain is often simultaneously bilateral, often severe in the neck, usually continuous for hours and often incessant; true precipitants do not occur.

Post-herpetic trigeminal neuralgia is a burning and shooting pain, sometimes exacerbated by tactile stimuli. On the other hand there is a history of shingles, the affected area is scarred at least slightly and is anaesthetic or analgetic, the pairo is incessant and there are no true precipitants. The almost invariable site is the ophthalmic divisionoํㅜㄱ Unfortunately patients with this disorder are willing to undergo trigeminal injection, rhizotomy or tractotomy, but none of these gives them any relief, nor does any surgical measure except leucotomy.

Migrainous neuralgia and ciliary neuralgia (Harris, 1936, 1940a) occur in severe attacks which may begin suddenly and last as little as ten minutes; conjunctival flushing and lacrimation are prominent features, especially in ciliary neuralgia. However, the only sites are the eye, its neighbourhood and the temple; the attacks often begin gradually, last usually several and sometimes many hours, and are seldom clearly precipitated. Some cases are definitely relieved by trigeminal injection or rhizotomy.

Glossopharyngeal neuralgia consists of brief paroxysms of agonizing, red-hot stabs brought on usually by swallowing and coughing but also sometimes by movements of the tongue or the jaw. It differs from tic douloureux in its much greater rarity and in its sites; these are the back of the tongue, the soft palate, the tonsil, the pharynx and the eardrum. Owing to the considerable overlap between the fifth and ninth nerves and the impossibility of precisely locating any severe pain, the distinction between the two neuralgias may be far from easy. Some patients with glossopharyn- 
TABLE I

\section{Diagnosis of Tic Douloureux}

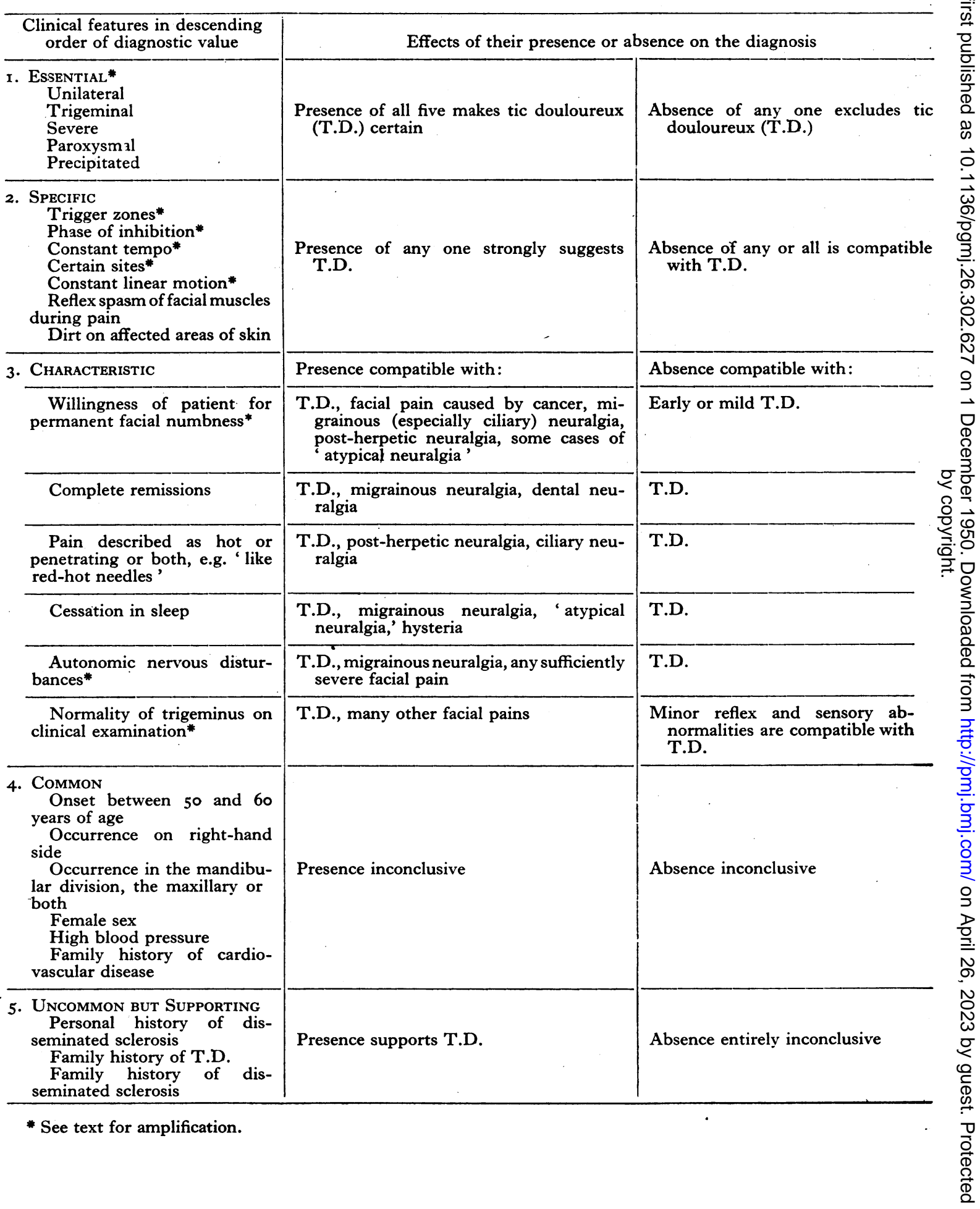


geal neuralgia give a peculiar, involuntary, halfsuppressed cough or choking sound at the height of some of their paroxysms. Choosing a time when nearly every act of swallowing is bringing on the pain, one can spray the affected side of the throat with a 5 per cent. solution of cocaine; if this renders swallowing painless the neuralgia is glossopharyngeal.

Tumours. Primary trigeminal tumours were divided by Krayenbühl (1936) into those of the sensory root causing facial numbness, and those of the ganglion causing continuous pain. Cohen (1933) described a neuroma of the ganglion causing paroxysmal pain but without precipitants. These primary tumours are extremely rare. Tumours secondarily involving the trigeminus in the cerebello-pontine angle cause pain which is continuous in some cases, paroxysmal in others. Nearly always there is also trigeminal analgesia or anaesthesia and often paralysis of the motor root. Some writers have maintained that true tic douloureux can be symptomatic of a tumour in this situation. The extremest of them was Dandy (1934) who maintained that gross lesions affecting the trigeminal sensory root were to be found in 60 per cent. of all cases of tic douloureux. One case of a tumour combined with tic douloureux was reported by Weisenburg (I910), two by Sjöqvist (1938, 1939) and 24 by Revilla (1946). The diagnostic criteria used in these cases were not set out in full and therefore the existence of symptomatic tic douloureux is still somewhat doubtful, but the possibility should be remembered, especially, it seems, when nerve deafness of recent onset is found on the side of the pain.

The following two conditions are sequels to the radical treatment of tic douloureux.

The syndrome of painful numbness is a severe form of the common post-operative paraesthesiae. It begins insidiously a few weeks or months after the radical treatment, usually in cases with ophthalmic-division anaesthesia. Itching, prickling, aching or drawing sensations are felt, most commonly in and around the eye. They are continuous and not precipitated. By occurring during sensory tests they often give a false impression that sensation has returned to the anaesthetic area, and so lead to the conclusion that a relapse of tic douloureux has begun.

' Gasserian ghosts' are shooting sensations in the same sites as the former pain of tic douloureux, equally intermittent but wholly or nearly painless and not precipitated. Patients often fear that they may herald a relapse.

\section{Treatment}

1. Palliative

Trousseau (I86I) said of tic douloureux: ' I con- fess openly that I have never cured a single patient.' From croton oil to Christian Science, from hypnotism to hot air, almost every imaginable remedy has had its spurious triumphs. Since the precipitants include emotion and exertion it follows that sedation, rest and even the mere fact of treatment, no matter with what, will tend to give relief. Other apparent successes are really natural remissions.

Trichlorethylene in a pure state does not, as was once believed, cause trigeminal sensory loss. In anaesthetic practice, and probably also in cases of industrial poisoning, this effect was produced by dichloro-acetylene, a toxic and dangerous impurity. If trichlorethylene influences tic douloureux, it must do so by inducing transient general analgesia, or vasodilatation, or both.

A synthetic organic copper compound ('Cuprelone ') was tried by Campbell (1948) in I 3 cases, only four of which he described in detail. In one there was a relapse within three months; two were followed for one year and one for one and a half years without relapse. No conclusion can be drawn from this work.

Nicotinic acid is a rational palliative which probably produces its effect by vasodilatation. Alone of medical treatments it has some suppore from a controlled experiment (Adams and Robin 8 son, I94I). The dose is $50 \mathrm{mgm}$. by mouth fou times a day. High blood pressure is an indication for beginning with $25 \mathrm{mgm}$.; ultimately $100 \mathrm{mgm} \stackrel{\text { F }}{2}$ or more may be needed. Patients must be told to expect intense prickling and flushing of the skin and perhaps faintness soon after each dose. Benefit may be obtained without these side effects, but until they occur a full trial of this treatment has not been made. Phenobarbitone, gr. $\frac{1}{2}$ b.d., may be added as a sedative.

\section{Radical}

Tic douloureux is relieved by the interruption of all the pain-conducting primary sensory neurones which connect the painful areas at the periphery with the nucleus of the descending trigeminal tract. The interruption will be effective at any point except, perhaps, very close to the periphery. Any interruption distal to the trigeminal ganglion, however, is sure to be temporary, for the centrifugal branches of the primary sensory neurones have great powers of regeneration. Any complete interruption proximal to the ganglion is sure to be life-long, for the centripetal branches from the root entry zone in the pons downwards have no sheaths of Schwann; their terminal portions within the brain stem will begin to degenerate as soon as they are cut off from their parent cells in the trigeminal ganglion and will be quite incapable of regeneration. 
TABLE 2

Five Methods of Radical Treatment Compared

\begin{tabular}{|c|c|c|c|c|c|}
\hline $\begin{array}{c}\text { Features in descending order of } \\
\text { importance }\end{array}$ & $\begin{array}{l}\text { Kirschner's } \\
\text { method }\end{array}$ & $\begin{array}{c}\text { Intracranial } \\
\text { alcohol }\end{array}$ & $\begin{array}{l}\text { Rhizotomy, } \\
\text { subtemporal }\end{array}$ & $\begin{array}{l}\text { Rhizotomy, } \\
\text { suboccipital }\end{array}$ & $\begin{array}{l}\text { Medullary } \\
\text { tractotomy }\end{array}$ \\
\hline $\begin{array}{l}\text { Operative death rate in selected } \\
\text { cases and in the best hands }\end{array}$ & - & 一 & $0.5 \%$ (abfgo) & $2-3 \%(c d o)$ & $\begin{array}{l}\text { Variable: } \quad 2-4 \% \\
(e o q)\end{array}$ \\
\hline $\begin{array}{l}\text { Operative death rate in selected } \\
\text { cases and in all hands at a good } \\
\text { clinic }\end{array}$ & - & - & $2 \%(i j)$ & Not stated & Not stated \\
\hline $\begin{array}{l}\text { Operative death rate in unselected } \\
\text { cases }\end{array}$ & $0.72 \%(l)$ & Infinitesimal & Unknown & Unknown & Unknown \\
\hline Primary success rate & $75 \%(l)$ & $94 \% *$ & $99 \%$ (?) & $99 \%(?)$ & Not stated \\
\hline $\begin{array}{l}\text { Relapse rate in all operations, prim- } \\
\text { ary failures included }\end{array}$ & $45 \%(l)$ & $10-15 \% *$ & $5 \%(h)$ & $18 \%(o)$ & $\begin{array}{l}30 \%(o) \\
5 / 6(j) \\
1 / 13(e)\end{array}$ \\
\hline $\begin{array}{l}\text { Relapse rate in complete operations, } \\
\text { primary failures included }\end{array}$ & - & - & $2 \%(h)$ & Not stated & 一 \\
\hline $\begin{array}{l}\text { Relapse rate in partial operations, } \\
\text { primary failures included }\end{array}$ & 一 & 一 & $8 \%(h o)$ & Not stated & 一 \\
\hline $\begin{array}{l}\text { Feasibility of selective attack on the } \\
\text { painful region or regions }\end{array}$ & Small $(r)$ & Small & Great & Not great & $\begin{array}{l}\text { Only on ophthalmic } \\
\text { division }\end{array}$ \\
\hline Preservation of the motor root & $80 \%(?)(m)$ & $100 \%$ & $80 \%(h)$ & $\begin{array}{l}\text { Very fre- } \\
\text { quent }\end{array}$ & $100 \%$ \\
\hline Keratitis requiring tarsorrhaphy & $5 \%(?)(s)$ & $15 \% *$ & $5-10 \%(h p)$ & $2 \%(0)$ & $\circ \%(?)$ \\
\hline External ocular palsies & $3 \%(s)$ & $2 \% *$ & $\mathrm{I} \%(h)$ & $\circ \%(?)$ & $\circ \%(?)$ \\
\hline Facial palsy & $\begin{array}{l}\text { Not stated; } \\
\text { perhaps } \circ \%\end{array}$ & Rare & $5-10 \%(j k o)$ & $3 \%(0)$ & $\circ \%(?)$ \\
\hline Operative pain & None & Severe & None & None & $\begin{array}{l}\text { Agonizing with local } \\
\text { anaesthesia (en) }\end{array}$ \\
\hline Time in hospital & A few days & 3 days & ro days & Io days & 2 weeks (?) \\
\hline Post-operative paraesthesiae & Common & Common & Common & Common & Common $(e j)$ \\
\hline
\end{tabular}

* Based on the author's series of roo consecutive cases.

Letters in parentheses refer to Bibliography.

Peripheral alcohol injection, in view of the above facts, ought perhaps to be called semiradical treatment. It may be performed at the foramen ovale, at the foramen rotundum or the infra-orbital foramen, and at the supra-orbital foramen or notch. The impermanence of the results has sometimes been adduced as a positive advantage, on the ground that it gives a foretaste of the numbness which later will be needed permanently. On the contrary the patient with tic douloureux wants to be freed from it once for all, and peripheral injections are therefore of little value. An exception is the rare case with pain limited to the ophthalmic division, which a supraorbital injection will relieve without numbing the cornea. Peripheral neurotomy and neurectomy are obsolete.

Interruption of the pain fibres between the trigeminal ganglion and the nucleus of the descending tract may be achieved at three sites:

I. In the pars triangularis of the sensory root by Kirschner's method, intracranial injection or subtemporal rhizotomy.

2. In the pars compacta of the sensory root close to the pons by suboccipital rhizotomy.

3. In the descending tract by medullary tractotomy.

There are thus five radical mathods which, in Table 2, are compared from 15 important aspects. Most of the figures given are inevitably approxi- 
mations, reached by the assessment and balancing of many statements which cannot even be summarized here. The main sources of information are indicated in Table 2 by letters from which they can be traced in the bibliography. In the case of alcohol injection the figures marked with asterisks are from my own series for want of a better source. By far the most reliable statistics for any method are those of Grant (1938) for over 900 subtemporal rhizotomies, but even these are partially vitiated by his inclusion of small numbers of cases in which tic douloureux was not diagnosed, gangliectomies and sections of the peripheral divisions. 'Relapse rate' has no precise meaning; one should give a five-year or ten-year relapse rate based on an exhaustive follow-up, but apparently no worker has done this for tic douloureux. The crude relapse rate, if there is any adequate follow-up, must increase with the duration of the series of treated cases; Grant's series, beginning in 1901, has a greater duration than any other.

Kirschner's method combines an elaborate needleguiding apparatus with coagulating diathermy. Partly by head measurements, partly by radiography, the angulation and depth of the needle are predetermined, the apparatus is set accordingly and under general anaesthesia the needle is driven home; it passes the foramen ovale at the first thrust in 90 per cent. of cases (Kirschner, 1936). The foramen passed, the stilet of the needle is replaced by an electrode and, still under general anaesthesia, the coagulating current is switched on.

The dangers are obvious. By the anterior approach, which is the one used, the needle point has only to go a little too high and it will encounter the temporal lobe of the brain (Gutnikoff, 1925); it is never more than a few millimetres from the cavernous sinus. Kirschner (1933) reported one case each of 'deterioration of vision,' tenth-nerve palsy, recurrent-nerve paresis and otitis media; Zenker (1938) two contralateral hemiplegias which 'diminished extensively within some months.' Kirschner emphasized that a coagulation takes only 5 minutes and that 12 patients can easily be treated in one morning between major operations.

Intracranial injection acts less on the trigeminal ganglion than on the pars triangularis (Morris, 1931; Cavina, 1932; Ferner, 1949; Penman and Smith, 1950). A better name than ganglion injection would be rhizolysis. Many neurolytic agents have been tried (Sicard, 1918; Putnam and Hampton, 1936) but nothing so far seems better than 90 or 100 per cent. ethyl alcohol. Clinically the resulting anaesthesia has been recorded as remaining unaltered for periods up to 16 years (Harris, 1920; Taptas, 1931; Carmichael and Woollard, r933); pathologically, in one case, destruction of the descending trigeminal tract has been demonstrated (Penman and Smith, 1950). The permanence of the effects in the best cases is beyond question.

On the other hand, 40 years and many thousands of injections have failed to establish the resulis on any sound numerical basis. No standard procedure exists and one man's success is another man's failure. Many so-called ganglion injections followed by relapse are probably injections of the mandibular nerve just proximal to the foramen ovale, with a spread of procaine and alcohol to involve the other two main peripheral divisions inside the skull.

Follow-ups by letter were made by Härtel (r 935) in a series of 137 cases, and by Harris (1940b) in 457 cases selected from the unrivalled total of not less than 2,500. I know of no other extensive follow-up.

I have reported the early results in 42 consecutive cases of tic douloureux which I had tried to treat by intracranial alcohol injection with a radiological aid (Penman, 1949). The same consecutive series now numbers a little over a hundred, and the follow-up of the first roo patients, injected between August 1947 and August 1950, can be described (Table 3 ).

Cases No. 3 and No. 13 in this series were thê̊ only two in which the foramen ovale was not passed. In No. 3 it could have been passed has the patient been willing; in No. I3 it was almost entirely obscured by a broad ossified ligament. In case No. 8 also the injection produced no sensory change. These three cases have therefore been followed up only by letter, one for three years and two for two and a half years. Cases 7 and 95, in which rhizotomies were done within a few weeks of the unsuccessful injections, were not followed up.

Case 95 will serve to illustrate the fact that the injections in this series were undertaken regardless of any likelihood of failure, for the patient had already undergone three attempts at alcohol injection and two at subtemporal rhizotcmy, all followed by relapses, and preliminary radiograms showed an ossified ligament partly obstructing the foramen ovale. All that was hoped of the injection was that it would reduce the patient's suffering until a suboccipital rhizotomy could be done; this aim was achieved.

The other 95 patients were examined by me on the second day after injection, classified into twoday successes and failures as defined in Table 3 , and also asked to attend a follow-up clinic at certain planned intervals. One patient attended in the fourth week after injection and then defaulted, but had had no pain up to this last attendance. In the remaining 94 cases absences 
TABLE 3

yoo Radiologically Aided Injections; Results at Follow-up

\begin{tabular}{|c|c|c|c|c|c|c|c|}
\hline & \multicolumn{3}{|c|}{$\begin{array}{l}\text { 'Two-day failures'; not all formerly painful } \\
\text { areas analgetic two days after injection }\end{array}$} & \multicolumn{3}{|c|}{$\begin{array}{l}\text { 'Two-day successes'; all formerly painful } \\
\text { areas analgetic two days after injection }\end{array}$} & \multirow[b]{2}{*}{$\begin{array}{l}\text { Grand } \\
\text { Totals }\end{array}$} \\
\hline . & $\begin{array}{l}\text { Actual failures; } \\
\text { relapses of tic } \\
\text { douloureux }\end{array}$ & $\begin{array}{l}\text { Potential failures; } \\
\text { no relapse yet }\end{array}$ & Totals & $\begin{array}{c}\text { Partial analgesia } \\
\text { some formerly } \\
\text { painless areas } \\
\text { not analgetic at } \\
\text { last examination }\end{array}$ & $\begin{array}{l}\text { Total analgesia; } \\
\text { whole tri- } \\
\text { geminal area } \\
\text { of injected } \\
\text { side analgetic } \\
\text { or anaesthetic at } \\
\text { last examination }\end{array}$ & Totals & \\
\hline $\begin{array}{l}\text { Examined at } 2 \frac{1}{2} \\
\text { years after in- } \\
\text { jection }\end{array}$ & & I & I & & 2 & 2 & 3 \\
\hline $\begin{array}{l}\text { Examined at } 2 \\
\text { years }\end{array}$ & $\begin{array}{l}\text { I }(\text { No. } 9) \\
\text { re-injected }\end{array}$ & & $\mathbf{I}$ & 5 & I I & 16 & 17 \\
\hline $\begin{array}{l}\text { Examined at } I^{\frac{1}{2}} \\
\text { years }\end{array}$ & $\begin{array}{l}\text { I (No. 3o) } \\
\text { incipient }\end{array}$ & & I & 4 & 6 & 10 & I I \\
\hline $\begin{array}{l}\text { Examined at } I \\
\text { year }\end{array}$ & & $\bullet \mathbf{I}$ & $\mathbf{I}$ & 8 & (I died) & 23 & 24 \\
\hline $\begin{array}{l}\text { Examined at } 6 \\
\text { months }\end{array}$ & $\begin{array}{l}\text { I (No. 84) } \\
\text { incipient }\end{array}$ & $\mathbf{I}$ & 2 & 2 & IO & 12 & 14 श \\
\hline $\begin{array}{l}\text { Examined at less } \\
\text { than } 6 \text { months } \\
\text { but at } 3 \text { weeks } \\
\text { or more }\end{array}$ & . & (1 defaulted) & 2 & 9 & I 5 & 24 & 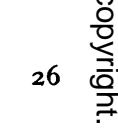 \\
\hline $\begin{array}{l}\text { Follow ed up } \\
\text { only by letter }\end{array}$ & I (No. 3) & (Nos. ${ }^{2}$ and 13 ) & 3 & & & & 3 \\
\hline Not followed up & $\begin{array}{l}2 \text { (Nos. } 7 \& 95) \\
\text { rhizotomies }\end{array}$ & & 2 & & & & 2 \\
\hline Totals & 6 & 7 & 13 & 28 & 59 & 87 & 100 \\
\hline
\end{tabular}

TABLE 4

Two-Day Success, Corneal Anaesthesia and Tarsorrhaphy in ioo Injections (Figures for the last 50 cases in parentheses)

\begin{tabular}{|c|c|c|c|c|c|c|c|c|c|}
\hline & & & & & \multicolumn{3}{|c|}{ Corneal anaesthesia } & \multirow{2}{*}{$\begin{array}{c}\text { No } \\
\text { corneal } \\
\text { anaesthesia }\end{array}$} & \multirow[b]{2}{*}{$\begin{array}{l}\text { Grand } \\
\text { Totals }\end{array}$} \\
\hline & & & & & Tarsorrhaphy & $\begin{array}{c}\text { No } \\
\text { tarsorrhaphy }\end{array}$ & Totals & & \\
\hline Two-day successes & . & . & . & . & r 5 (5) & $63(33)$ & $78(38)$ & $9(6)$ & $87(44)$ \\
\hline Two-day failures & $\cdots$ & . & $\cdots$ & . & - & $4(2)$ & $4(2)$ & $9(4)$ & $13(6)$ \\
\hline Totals .. & $\ldots$ & $\ldots$ & $\ldots$ & $\ldots$ & $15(5)$ & $67(35)$ & $82(40)$ & $18(10)$ & $100(50)$ \\
\hline
\end{tabular}


have been few and nearly all due to illness; soon after each absence a letter has been obtained from the patient, a relative or a hospital. Table 3, however, shows only actual attendances. Every patient at every attendance has been questioned and examined by me. The single death was due to rheumatic heart disease and occurred 13 months after injection.

This is a small, brief follow-up, but it is based on repeated sensory examinations in a series from which no exclusions have been made. Certain conclusions can therefore be drawn from it.

The primary success rate on a purely symptomatic basis is 97 per cent., for only patients No. 3, No. 7 and No. 95 had no remissions. Nos. 9, 30 and 84 had remissions of 22 , 10 and 6 months respectively; at 30 months No. 9 was re-injected, this time successfully. I prefer, however, to ininclude among the primary failures Nos. 8, 9 and 13 in whom little or no sensory loss was caused. The primary success rate is then 94 per cent.

Though the duration of the series is only three years it is perhaps worth noting that the crude relapse rate is $6 / 99$ (the one defaulter being excluded), and the crude complete relapse rate, judged by the need for further radical treatment, is $3 / 99$. Over a sufficiently long period all ${ }_{3} 3$ cases of twoday failure might relapse, but on the other hand in some of them death might occur first. Among the two-day successes some of those with partial anaesthesia may relapse owing to a spread of the tic douloureux to a hitherto uninvolved area, and even a few of those described as having total analgesia, if the sensory testing has been inaccurate, may also relapse. The crude relapse rate after many years can be put very roughly at 10 to 15 per cent.

Five out of the six primary failures were among the first 13 cases. Further evidence that the method has improved during the series is that the two-day successes, which are probably the best early criterion of the quality of the injections, numbered 87 in the whole series, 44 in the last 50 and 23 in the last 25. Similarly, in the whole series the incidence of keratitis requiring tarsorrhaphy was 15 per cent. of all cases and 18.3 per cent. of the eases with anaesthetic corneae; in the last $5^{\circ}$ cases the corresponding percentages were ro and 12.5 (Table 4). In one case of keratitis a permanent corneal opacity was left; in the other 14 there was no lasting visual impairment. In all cases with corneal anaesthesia the cornea was frequently examined during the first four weeks with an electric torch, and at the first appearance of punctate roughening the advice of an ophthalmologist was promptly sought. The indications for tarsorrhaphy may well have been stricter and earlier in this series than in some others in which enucleation of the eye was sometimes required. There were two external ocular palsies, one of them being an initially severe sixth-nerve lesion which entirely cleared up at the 12th week after injection. The other was manifested only by diplopia on looking downwards and was probably a mild fourth-nerve paresis; it occurred in the only defaulter and therefore could not be observed beyond the fourth week.

The operative death rate for intracranial injection is given in Table 2 as infinitesimal rather than nil because in the American, British, French and German literature $I$ have found reports of two, perhaps three, operative deaths (Gutnikoff, 1925; Coenen, 1932; Zander, 1933). Those interested in other equally rare complications may consult Koennecke (1917), Neugebauer (1918), N Kluge (1922), Jaensch (1926), Borsotti (1938) and last, but not least, Anonymous (1923) who paralysed all the cranial nerves on both sides except the second pair, and from this feat drew the general conclusion that 'alcohol injection of the Gasserian ganglion is fraught with serious danger.' The motor root is nearly always temporarily paralysed but invariably recovers.

Subtemporal and suboccipital rhizotomy are so well known that little comment is required apart from Table 2. The cases in which they are done are always to some extent selected. Frazier (r93 saw I,3I7 patients with tic douloureux and operated on 654 of them; of the other 663 some doubtless did not require radical treatment, but it is unlikely that none required it. Frazier and Gardner (r928) wrote: ' When the blood pressure is 200 or over the patient may receive an alcoholic injection.' Jefferson (1931) said: 'I have arbitrarily fixed 70 years as a limit,' that is, of age beyond which intracranial injection was to be used. The death rate from rhizotomy is so admirably low partly because the alternative of injection is available. It should be noted that ability to make a selective attack on the painful region, a point in which the subtemporal operation excels, carries with it the disadvantage that the relapse rate is thereby quadrupled.

For medullary tractotomy (Sjöqvist, 1937, 1938) cases are presumably selected at least as much as for rhizotomy. Probably the main advantage which this operation was expected to have was the avoidance of post-operative paraesthesiae; these were thought to be due to the interruption of the touch fibres, or perhaps to vary in severity with the total number of interrupted fibres of all kinds. On either theory they should be slight or absent 0 when only the descending tract is interrupted; this hope has proved vain. Important complications, partly preventable by a lower cut than Sjöqvist's original one, are ataxia and loss of 
postural sense in the arm on the side of operation and recurrent laryngeal palsy.

Criteria of a satisfactory radical operation. The ideal operation would combine a very low death rate even in unselected cases and even in merely competent hands, a low relapse rate, a low incidence of all serious complications and absence of operative pain. One fairly serious drawback, postoperative paraesthesiae, is shared by all present operations. The first thing to be avoided is the combination of a high or even an appreciable death rate with a high relapse rate, and on this score both Kirschner's method and medullary tractotomy must be rejected.

Subtemporal versus suboccipital rhizotomy. To judge by the available figures, the subtemporal approach gives the lower death and relapse rates. The suboccipital is superior only from the less important aspects of injury to the motor root, keratitis and facial palsy. It also has advantages when a posterior-fossa tumour is suspected, when previous unsuccessful rhizotomies or injections have spoilt the subtemporal approach, or when the neuralgia seems to be glossopharyngeal as well as trigeminal; when both sides are simultaneously and severely involved it enables both fifth nerves to be cut in a single operation. All these circumstances are rare but they make it desirable for the neurosurgeon to have the suboccipital operation at his command. Given a fine operator either approach is adequately safe and his indiviciual preference must decide the matter.

Rhizotomy versus injection. Intracranial injection is indispensable in some cases, and the only question is whether it should be tried in all. In my opinion it should; the virtual absence of a death rate outweighs the rather high relapse rate, the high incidence of keratitis and the operative pain. Of 1,000 patients treated first by rhizotomy about 20 will die of the operation. Of 1,000 patients treated first by intracranial injection, even if 200 relapse and all of the 200 have to have rhizotomies, only four will die; 16 lives in 1,000 will have been saved. This justifies not only the use of intracranial injection but the raising of it to the highest pitch of skill in order to reduce the relapse rate.

\section{Psychological}

Tic douloureux seems strange enough to the doctor; to the patient it often seems uncanny. He is troubled by the paradoxical contrast between his violent pain and his good general health, and by the complete unfamiliarity of his symptom both to himself and to his family and friends. Their sympathy is tinged with a bewilderment, and perhaps a scepticism, which isolate him. Great though his suffering is, he many wonder, especially during remissions, whether in some ill-defined sense it is imaginary or a form of madness. His hopes of being understood or cured are usually slender.

To enquire seriously into the pain, therefore, is to begin treatment. As soon as the diagnosis is clear one should tell the patient that his trouble is a rare one but well recognized and curable. Next, in some early cases, it is enough to explain that there may be long spells of freedom and to prescribe nicotinic acid and phenobarbitone. Most patients, however, should have the radical treatment described to them; they must be made to understand clearly (I) that the proposed numbness will be irrevocable and may prove positively disagreeable, (2) that if they are unlucky there may be temporary trouble with the eye. Questions should be encouraged and willingly answered; it is usually necessary to point out the distinction between facial numbness and facial paralysis. Once he has sufficient information the patient must choose or reject the treatment entirely by himself. To more intelligent patients I expound the pros and cons of rhizotomy and injection and let them make that choice also.

Radical treatment should never be given during a remission. Even if the pain ceases only as the $ᄋ$ patient comes into hospital he should be freely allowed to go home again and return with the next relapse. During injection he should be treated as an active collaborator and, within reason, told what is happening. As soon as a satisfactory result has been achieved he must be persuaded to try every means of bringing the pain on and so convince himself of his cure.

A follow-up clinic, one purpose of which is the collection of statistical data, is welcomed by nearly all these patients as an opportunity for showing gratitude. They also obtain necessary reassurance; for example, that the numbness is lasting, that ' Gasserian ghosts' do not mean imminent relapse or that a spread of the pain to the other side of the face is improbable.

The keys to this important part of treatment are patience, frankness and the handling of the patient as a responsible person.

\section{Summary}

The cure for established tic douloureux, but for very few other diseases, is permanent trigeminal anaesthesia. Too often this treatment is withheld when it should be given, and given when it should be withheld. Here the diagnosis of tic douloureux is described in detail and its differential diagnosis briefly. Palliative, radical and psychological aspects of treatment are reviewed. The results in Ioo consecutive cases treated by radiologically aided intracranial alcohol injection, and followed 
up by interview, are summarized. Because of the absence of a death rate this type of injection is recommended as the radical treatment to be tried first.

\title{
BIBLIOGRAPHY
}

(Letters in parentheses refer to Table 2)

ADAMS, W. E., and ROBINSON, R. (194I), Lancet, ii, 555. ANONYMOUS (1923), Brit. $\mathcal{F}$. Surg., 10, 573 .

BORSOTTI, I. (1938), Riv. oto-neuro-oftalm., $15,408$.

CAMPBELL, A. M. G. (1948), Lancet, ii, 690 .

CARMICHAEL, E. A., and WOOLLARD, H. H. (1933), Brain, 56, 109.

CAVINA, C. (1932), Riv. ital. Stomatol., 1, 3.

COENEN, H. (1932), Zbl. Chir., 59, 2963

COHEN, I. (1934), Arch. Neurol. Psychiat., Chicago, 31, 21 I.

(a) CUSHING, H.' W. (1920a), Amer. Y. med. Sci., 160, 157 .

(b) CUSHING, H. W. (1920b), $¥$. Amer. med. Ass., 75, 441.

(c) DANDY, W. E. (1929), Arch. Surg., Chicago, 18, 687.

(d) DANDY, W. E. (1932), Ann. Surg., 96, 787.

DANDY, W. E. (1934), Amer. . . Surg., 24, 447.

(e) FALCONER, M. A. (1949), Э. Neurol. Neurosurg. Psychiat., 12, 297.

FERNER, H. (1949), Nervenarzt, 20, 26.

(f) FRAZIER, C. H. (1925), Arch. Neurol. Psychiat., Chicago, 13, 378.

(g) FRAZIER, C. H. (1931) F. Amer. med. Ass., 96, 913

FRAZIER, C. H., and GARDNER, W. J. (1928), Surg. Gynec. Obstet., 47, 73 .

GLASER, M.' A.'(1928), Arch. Neurol. Psychiat., Chicago, 20, 537.

(h) GRANT, F. C. (1938), Ann. Surg., 107, 14.

(i) GRANT, F. C. (1943), Res. Publ. Ass. nerv. ment. Dis., 23, 408.

(j) GRANT, F. C. (1948), Amer. Y. Surg., 75, 42.

GUTNIKOFF, B. (1925), Arch. klin. Chir., 135, 79.

HAERTEL, F. F. (1935), Dtsch. med. Wschr., 6r, 1069.

HARRIS, W. (1920), Proc. R. Soc. Med., 13, Parts I and 2, Clinical Section, 62 .

HARRIS, W. (1936), Brit. med. F., i, 457.

HARRIS, W. (1940a), Lancet, ii, 48r.

HARRIS, W. (I940b), Brain, 63, 209.

HEAD, H. (1910), 'Allbutt and Rolleston's System of Medicine,' 2nd edition, London, Macmillan, 7, 540.

(k) HORRAX, G., and POPPEN, J. L. (1935), Surg. Gynec. Obstet.,

HUTCHIN 394. neuralgia,' London, John Bale and Danielsson.
JAENSCH, C. (1926), Klin. Mbl. Augenheilk., 77, 212.

JEFFERSON, G. (1931), Brit. med. $\mathcal{Y}$., ii, 879.

KIRSCHNER, M. (1933), Arch. klin. Chir., 176, 58 1.

KIRSCHNER, M. (1936), Ibid., 186, 325.

(l) KIRSCHNER, M. (I942), Munch. med. Wschr., 89, 235, 263.

KLUGE, A. (1922), Z. ges. Neurol. Psychiat. (Originalien), 76, 372. KOENNECKE, W. (1917), Dtsch. Z. Chir., x40, 225.

KRAYENBUEHL, H. (1936), Brain, 59, 337.

LEWY, F. H., and GRANT F. C. (1938), Arch. Neurol. Psychiat., Chicago, 40, 1126.

MCAULIFFE, G. W., GOODELL, H., and WOLFF, H. G. (1943), Res. Publ. Ass. nerv. ment. Dis., 23, 185.

MORRIS, L. (1931), Lancet, i, I22.

NEUGEBAUER, F.' (1918), Zbl. Chir., 45, 565.

(m) ODDSSON, B. (1944), Acta Psychiat., Kbh., 19, 293.

(n) OLIVECRONA, H. (1942), Arsh. Neurol.'Psychiat., Chicago,

(o) OLIVECRONA, H. (1947), Acta Psychiat., Kbh., Suppl. 46, 268.

(p) PANNABECKER, C. L. (1944), Arch. Ophthal., N.Y., 32, 456. PENMAN, J. (1949), Lancet, ii, 268.

PENMAN, J., and SMITH, M. C. (1950), f. Neurol. Neurosurg. Psychiat., 13, 36.

PUTNAM, T. J., and HAMPTON, A. O. (1936), Arch. Neurol. Psychiat., Chicago, 35, 92.

(q) RANEY, R., RANEY, A. A., and HUNTER, C. R. (1948), Trans. Amer. neurol. Ass., 73, 148.

REVILLA, A. G. (1946), $\mathcal{Y}$. Neurosurg., 4, 233.

SICARD, J.-A. (r918), Med. Pr., 106, 60.

SJOEQVIST, O. (1937), Zbl. Neurochir., 2, 274.

SJOEQVIST, O. (1938), Acta Psychiat., Kbh., Suppl. 17.

SJOEQVIST, O. (1939), Acta chir. scand., 82, 201.

TAPTAS, N.'(I93 I), Pr. méd. 39,239

TAPTAS, N. (1931), Pr. méd." 39, 239.

OUSSEAU, A. (1861), 'Clinique médicale de l'Hôtel-Dieu de Paris,' Ist edition, vol. 2, Paris, Baillière. Translated in Publ New Sydenham Soc., 1868, 35, 105.

WEISENBURG, T. H. (1910), $¥$. Amer. med. Ass., 54, 1600.

ZANDER, P. (1933), Arch. klin. Chir., 178, 242.

(r) ZENKER, R. (1934), Med. Welt, 8, 14

(s) ZENKER, R. (1938), Ergebn. Chir. Orthop., 31, I.

\section{CERVICAL}

\section{PROTRUSION}

\author{
By Valentine Logue, M.R.C.P., F.R.C.S.
}

Assistant Neurological Surgeon to St. George's Hospital and the Maida Vale Hospital for Nervous Diseases. Neurological Surgeon to the Royal National Orthopaedic Hospital

The prolapsed intervertebral disc in the lumbar region which compresses a nerve root to produce sciatica has become, since its original description in 1934, a commonplace in diagnosis, with its methods of conservative and surgical treatment firmly established, and it seemed only a question of time before the symptomatology of prolapsed discs elsewhere in the spinal column was recognized. In the case of the cervical region however this recognition was somewhat tardy. The first detailed description to be published in an English journal of lateral protrusions causing brachial neuritis appeared only five years ago', and the various syndromes of spinal cord compression from median protrusions and their tendency to mimic degenerative diseases of the cord, although first described in 1928, are even at the present time not widely known.

It is possible for a cervical protrusion, depending on its relationship to the nervous structures, to produce three different syndromes, which are illustrated in Fig. I and which were first described by Stookey: ${ }^{2}$

I. A lateral protrusion causing pressure on a nerve root to produce brachial neuritis.

2. A more medial protrusion compressing one half of the spinal cord with a Brown-Séquard syndrome.

3. Midline protrusion causing bilateral spinal cord compression.

Occasionally a prolapse may start with symptoms of root compression and then increase in size and produce successively unilateral and then bilateral cord involvement.

\section{Lateral Protrusion with Nerve Root Compression}

Anatomy

There are only six intervertebral discs in the 